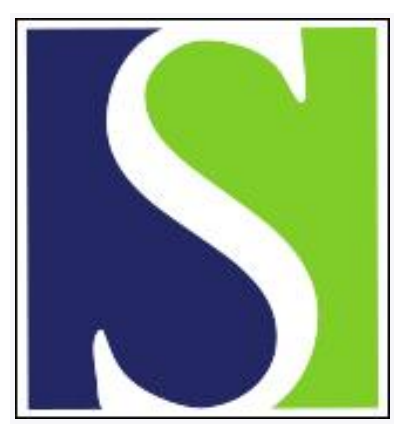

Scand J Work Environ Health 1983;9(3):291-297

https://doi.org/10.5271/sjweh.2408

Issue date: Jun 1983

Left-sided carpal tunnel syndrome in butchers.

by Falck B, Aarnio P

This article in PubMed: www.ncbi.nlm.nih.gov/pubmed/6612270

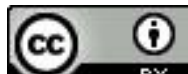

This work is licensed under a Creative Commons Attribution 4.0 International License 


\title{
Left-sided carpal tunnel syndrome in butchers
}

\author{
by Björn Falck, MD, ${ }^{1}$ Pertti Aarnio, $\mathrm{MD}^{2}$
}

\begin{abstract}
FALCK B, AARNIO P. Left-sided carpal tunnel syndrome in butchers. Scand $j$ work environ health 9 (1983) 291-297. Butchers from two slaughterhouses were studied for carpal tunnel syndrome. The diagnosis was based on subjective symptoms and electroneurography. In about half of the otherwise healthy butchers there were various degrees of the syndrome in the nondominant hand, or, if the syndrome was bilateral, the nondominant side was more affected. So far two of the subjects have been operated on. The operative findings and results were consistent with carpal tunnel syndrome. The underlying cause for this occupational disorder is probably mechanical stress on the left hand. Various tools are held in the right hand, while the carcass is lifted, torn, and handled with the left hand. The butchers considered the load on the left hand more strenuous than the one on the right. The prolonged heavy grasping with the fingers of the left hand probably leads to thickening of the synovial membrane of the finger flexors within the carpal tunnel. The carpal tunnel is a relatively rigid structure, and an increased diameter of the flexor tendons may cause the carpal tunnel syndrome. This small cluster sample of butchers is not adequate for epidemiologic conclusions. However, carpal tunnel syndrome seems to be an important occupational disorder among butchers.
\end{abstract}

Key terms: entrapment neuropathies, median nerve, occupational neuropathy.

Entrapment of the median nerve at the wrist, also called carpal tunnel syndrome, is a relatively common disorder, especially in middle-aged women (13). This syndrome is often connected to local factors in the wrist, such as rheumatoid arthritis (10), distal fractures of the radius (11), or tenosynovitis of the finger flexors (12). Also various disorders causing swelling of the wrist, such as pregnancy (16), myxedema, and acromegaly may lead to the occurrence of the carpal tunnel syndrome. Diabetes is often associated with this syndrome (13). Sometimes there is no obvious cause for the syndrome; in such idiopathic cases the cross-sectional area of the carpal tunnel is often smaller than in referents (4). In a high proportion of patients the syndrome occurs bilaterally, but it is usually more severe on the dominant side (15).

I The Rehabilitation Research Center of the Social Insurance Institution, Turku, Finland.

2 Department of Surgery, Satakunta Central Hospital, Pori, Finland.

Reprint requests to: Dr B Falck, The Rehabilitation Research Center of the Social Insurance Institution, Peltolantie 3, SF-20720 Turku 72, Finland.
In cases of occupational nerve lesions the work methods of the patient gradually lead to nerve damage. Toxic neuropathies or nerve lesions caused by single accidents are not included in this category (17). Repeated mechanical injuries to the palmar side of the wrist and heavy work involving grasping with the fingers may lead to carpal tunnel syndrome. This syndrome has been described as an occupational disorder in, among others, cigar makers (1), carpenters (7), bakers (9), and dentists (19). So far there are no adequate epidemiologic studies on the incidence and prevalence of the disease. Cannon et al (3) reported 30 cases of carpal tunnel syndrome among an industrial population of 20,000 .

Patients with carpal tunnel syndrome usually complain of numbness in the fingers (I-IV) innervated by the median nerve; often there is also diffuse pain in the shoulder region. Typically these symptoms are worse at night; the patient usually wakes up and has to shake his hands to relieve the numbness. Often the symptoms are aggravated during manual work. The diagnosis of carpal tunnel syndrome is confirmed by electroneuromyography. 
In mild and moderate cases there is slowing of the sensory conduction velocity of the median nerve at the wrist. In moderate and severe cases there is also prolongation of the motor distal latency of the median nerve from the wrist to the thenar muscles, and in needle electromyography fibrillations and positive sharp waves are found in the thenar muscles (2). Clinical tests are of limited value in the diagnosis of the syndrome (18).

Recently we encountered two male butchers with carpal tunnel syndrome on the left side within a short period of time. Both subjects were operated on and their symptoms disappeared. This somewhat unusual presentation of carpal tunnel syndrome on the nondominant side led us to study a small number of butchers to determine whether the syndrome could be a more common disorder in butchers.

\section{Subjects}

All butchers from two slaughterhouses in the town of Pori (population 80,000) were invited to take part in the study. Altogether 19 butchers were included in the sample, $17(89 \%)$ of whom participated. All participants were butchers; meat cutters were not included. The butchers worked with beef, as well as with pork. They were all male. Their ages ranged from 23 to 56 (mean 38.8, SD 10.0) years. The subjects had been working as butchers for 3 to 32 (mean 15.3, SD 9.3) years. Most of them were heavily built, muscular, and to varying degrees obese, their height was 168-193 (mean 178, SD 7.8) $\mathrm{cm}$ and their weight ranged from 72 to 116 (mean 92.9, SD 12.6) kg. They were all right-handed. None of them had any systemic disease or relevant injuries, such as old fractures in the upper extremities.

\section{Methods}

Each subject was interviewed and examined clinically (by PA). In addition the sensory nerve conduction velocity of the median and ulnar nerves at the wrist were measured (by BF).

\section{Subjective symptoms}

Numbness in the region innervated by the median nerve was considered separately for occurrence at night and at work. If the subject woke up at night three to six times a week because of numbness in the hands, the subjective symptoms at night were considered slight $(=1)$. If he woke up more than six times a week, the symptoms were considered moderate $(=2)$. Similarly the symptoms at work were considered slight $(=1)$ if numbness occurred three to six times a week and moderate $(=2)$ if they were more frequent. If moderate symptoms were present both at night and at work, the symptoms were considered marked.

\section{Clinical tests}

The clinical tests performed were Phalen's test, Tinel's sign, and the cuff test. In Phalen's test the wrist was maximally flexed for $1 \mathrm{~min}$; the test was positive if there was numbness in the fingers innervated by the median nerve. Tinel's sign was positive if tapping of the carpal tunnel caused paresthesia in the region innervated by the median nerve. In the cuff test a cuff was placed on the upper arm at a pressure between the systolic and the diastolic pressure; if numbness appeared after $1 \mathrm{~min}$ in the fingers innervated by the median nerve, the cuff test was considered positive.

\section{Nerve conduction velocity measurements}

The antidromic sensory nerve conduction velocity was measured with surface electrodes (Disa 13L22) with standard electromyographic equipment (Tönnies DA I $R$ ). The sensory conduction velocity of the median nerve was measured on both sides between the wrist and the ulnar side of the forefinger, and that of the ulnar nerve was measured between the wrist and the ulnar side of the index finger. The temperature of the hand was measured. If the temperature of the palm was less than $30^{\circ} \mathrm{C}$, the hands were warmed. The sensory conduction velocity values from 20 healthy male referents, aged 19-46 (mean $34.2, \mathrm{SD}$ $10.9)$ years, are shown in table 1 . In addition to the sensory conduction velocity in the median and ulnar nerve the difference 
between the two was also taken into consideration (6). If the velocity of the median nerve was between $44-41 \mathrm{~m} / \mathrm{s}$ (minus $2-3$ $\mathrm{SD}$ ) or $7-9 \mathrm{~m} / \mathrm{s}$ slower (minus $2-3 \mathrm{SD}$ ) than in the ulnar nerve on the same side, the finding was considered slightly abnormal. If the conduction velocity in the median nerve at the wrist was below $41 \mathrm{~m} / \mathrm{s}$ or 9 $\mathrm{m} / \mathrm{s}(>3 \mathrm{SD})$ slower than that of the ulnar nerve, the finding was considered definitely abnormal.

\section{Body mass index}

To quantitate the degree of obesity, body mass index (BMI) (8) was calculated, BMI $=$ weight $/$ height $^{2}\left(\mathrm{~kg} / \mathrm{m}^{2}\right)$. The normal values for Finnish subjects have been taken from a study of Heliövaara \& Aromaa (5). Normal values are those below $27.00 \mathrm{~kg} / \mathrm{m}^{2}, 10 \%$ overweight is above 27.00 $\mathrm{kg} / \mathrm{m}^{2}, \quad 20$ \% overweight above 30.00 $\mathrm{kg} / \mathrm{m}^{2}$, and $30 \%$ overweight above 32.00 $\mathrm{kg} / \mathrm{m}^{2}$.

\section{Results}

The results of the study have been summarized in table 2 .

\section{Right side}

Thirteen subjects ( $76 \%$ ) had no subjective symptoms of the carpal tunnel syndrome on the right side; however, two of the thirteen $(F, J)$ had definite slowing of the sensory conduction velocity of the median nerve at the wrist. Three subjects $(\mathrm{C}, \mathrm{H}, \mathrm{I})$ had slight subjective symptoms, one of the three (C) also had definite slowing of the sensory conduction velocity of the median nerve, and the other two $(\mathrm{H}, \mathrm{I})$ had a normal sensory conduction velocity of the median nerve. One subject (G) had marked subjective symptoms on the right side; he also had definite slowing of the sensory conduction velocity of the median nerve.

\section{Left side}

There were seven subjects (41\%) with no subjective symptoms on the left side; three of the seven (D, M, N) had slowing of the sensory conduction velocity in the median nerve. Three subjects had slight symptoms (C, F, H); two of the three (C, F) had slowing of the sensory conduction velocity of the median nerve. Five subjects had moderate subjective symptoms (B, I, J, $\mathrm{K}, \mathrm{L}$ ); all of the five also had definite slowing of the sensory conduction velocity of the median nerve. Two subjects had marked subjective symptoms ( $G, Q$ ), and they also had definite slowing of the sensory conduction velocity of the median nerve. Altogether there were nine subjects $(53 \%)$ with subjective symptoms and electrophysiological evidence of carpal tunnel syndrome on the left side. In addition there were three subjects with subclinical carpal tunnel syndrome; they were asymptomatic but had slight slowing of the sensory conduction velocity in the median nerve.

All the subjects with carpal tunnel syndrome on the right side also had abnormalities on the left side. In all cases except one (C), the carpal tunnel syndrome was more severe on the left side.

\section{Clinical signs}

The clinical tests were rarely positive although there were typical subjective symptoms and electrophysiological findings. Tinel's sign was negative in all the subjects. Phalen's sign was positive in three hands. In two of the three there were no symptoms, and the sensory conduction velocity of the median nerve was within normal limits. The cuff test was positive in two subjects bilaterally $(G, L)$. In the four hands of the two subjects there was carpal tunnel syndrome in three, and one was normal.

Table 1. Antidromic sensory conduction velocity of the median and ulnar nerve at the wrist of 20 male referents aged $18-57$ (mean $36.3, S D 12.4$ ) years.

Median nerve (wrist-forefinger)

Ulnar nerve (wrist-index finger)

Ulnar-median difference (absolute value)

Sensory conduction velocity $(\mathrm{m} / \mathrm{s})$

\begin{tabular}{rccc}
\hline Mean & SD & Minimum & Maximum \\
\hline 50.3 & 3.1 & 44.5 & 58.1 \\
50.6 & 3.1 & 45.9 & 55.2 \\
2.6 & 2.0 & 0 & 6.8 \\
\hline
\end{tabular}


Table 2. Findings for individual subjects.

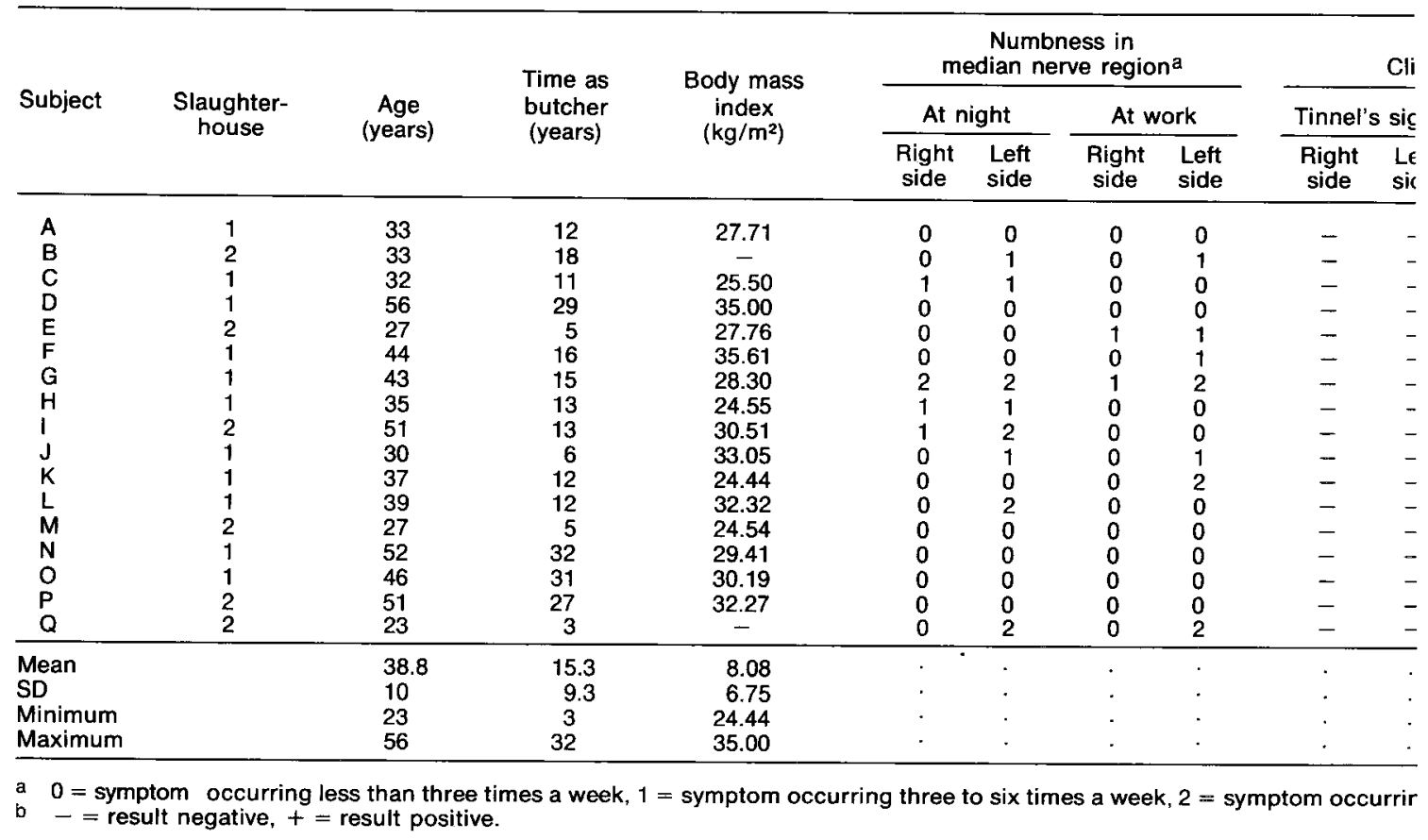

Table 3. Age, work time, and body mass index. ${ }^{a}$

\begin{tabular}{|c|c|c|c|c|c|c|c|}
\hline & \multirow{2}{*}{$\begin{array}{l}\text { Number of } \\
\text { subjects }\end{array}$} & \multicolumn{2}{|c|}{ Age (years) } & \multicolumn{2}{|c|}{$\begin{array}{c}\text { Time as butcher } \\
\text { (years) }\end{array}$} & \multicolumn{2}{|c|}{$\begin{array}{l}\text { Body mass index } \\
\left(\mathrm{kg} / \mathrm{m}^{2}\right)\end{array}$} \\
\hline & & Mean & SD & Mean & SD & Mean & SD \\
\hline $\begin{array}{l}\text { Group I, no carpal } \\
\text { tunnel syndrome }\end{array}$ & 5 & 38.4 & 9.8 & 17.6 & 10.9 & 28.48 & 2.93 \\
\hline $\begin{array}{l}\text { Group II, subclinical } \\
\text { carpal tunnel syndrome } \\
\text { Ğroup III, carpal }\end{array}$ & 3 & 45.0 & 15.7 & 13.0 & 16.5 & 29.65 & 5.23 \\
\hline tunnel syndrome & 9 & 36.9 & 8.5 & 11.8 & 4.7 & 29.92 & 4.09 \\
\hline
\end{tabular}

a The body mass index of two subjects with carpal tunnel syndrome were not available.

\section{Age and work time}

The subjects were divided into three groups according to the subjective symptoms and electrophysiological findings. Group I had no signs of carpal tunnel syndrome. Group II had subclinical carpal tunnel syndrome (no subjective symptoms of the syndrome, but a normal sensory conduction velocity of the median nerve). Group III had subjective symptoms and electrophysiological abnormalities. The mean ages and time spent in this type of work is seen in table 3 . The three groups did not differ significantly $(p>0.05$, analysis of variance) in these two aspects. However it should be noted that all four of the subjects (D, N, O, P) who had been working as butchers for more than 20 years were free of symptoms, and only two of the four $(\mathrm{O}, \mathrm{N})$ had subclinical carpal tunnel syndrome on the left side. There were four subjects (E, I, M, Q) who had been working less than 10 years as butchers. Two of the four had carpal tunnel syndrome (I, Q), one had subclinical carpal tunnel syndrome (M), and one was normal (E). 


\section{Discussion}

\begin{tabular}{|c|c|c|c|c|c|c|c|}
\hline \multirow{2}{*}{\multicolumn{2}{|c|}{ en's test }} & \multirow{2}{*}{\multicolumn{2}{|c|}{ Cuff test }} & \multicolumn{4}{|c|}{ Sensory conduction velocity $(\mathrm{m} / \mathrm{s})$} \\
\hline & & & & \multicolumn{2}{|c|}{ Right side } & \multicolumn{2}{|c|}{ Left side } \\
\hline$t$ & $\begin{array}{l}\text { Left } \\
\text { side }\end{array}$ & $\begin{array}{l}\text { Right } \\
\text { side }\end{array}$ & $\begin{array}{l}\text { Left } \\
\text { side }\end{array}$ & $\begin{array}{l}\text { Median } \\
\text { nerve }\end{array}$ & $\begin{array}{l}\text { Ulnar } \\
\text { nerve }\end{array}$ & $\begin{array}{l}\text { Median } \\
\text { nerve }\end{array}$ & $\begin{array}{l}\text { Ulnar } \\
\text { nerve }\end{array}$ \\
\hline & $\begin{array}{l}\overrightarrow{+} \\
- \\
- \\
- \\
- \\
- \\
- \\
- \\
- \\
- \\
- \\
- \\
+ \\
+ \\
\end{array}$ & $\begin{array}{l}- \\
- \\
- \\
- \\
- \\
- \\
+ \\
- \\
- \\
- \\
- \\
+ \\
- \\
- \\
- \\
-\end{array}$ & $\begin{array}{l}- \\
- \\
- \\
- \\
- \\
- \\
+ \\
- \\
- \\
- \\
\overline{-} \\
- \\
- \\
- \\
- \\
-\end{array}$ & $\begin{array}{l}52 \\
50 \\
37 \\
47 \\
50 \\
42 \\
43 \\
44 \\
48 \\
44 \\
48 \\
50 \\
50 \\
48 \\
51 \\
50 \\
50 \\
\end{array}$ & $\begin{array}{l}52 \\
53 \\
47 \\
53 \\
53 \\
52 \\
55 \\
50 \\
54 \\
54 \\
51 \\
53 \\
54 \\
52 \\
54 \\
51 \\
53 \\
\end{array}$ & $\begin{array}{l}51 \\
42 \\
40 \\
42 \\
46 \\
40 \\
40 \\
45 \\
41 \\
41 \\
42 \\
36 \\
46 \\
35 \\
54 \\
44 \\
42\end{array}$ & $\begin{array}{l}50 \\
54 \\
46 \\
56 \\
52 \\
51 \\
56 \\
51 \\
52 \\
50 \\
53 \\
51 \\
55 \\
50 \\
56 \\
52 \\
54\end{array}$ \\
\hline &. & $\begin{array}{l}. \\
\cdot \\
\cdot \\
\end{array}$ & $\dot{.}$ & $\begin{array}{c}47.3 \\
4.0 \\
37 \\
52 \\
\end{array}$ & $\begin{array}{l}52.4 \\
1.9 \\
47 \\
55\end{array}$ & $\begin{array}{c}42.8 \\
4.7 \\
35 \\
54\end{array}$ & $\begin{array}{c}52.3 \\
2.7 \\
46 \\
56\end{array}$ \\
\hline
\end{tabular}

re than six times a week.

\section{Body mass index}

According to the body mass index only four subjects were not overweight $(\mathrm{C}, \mathrm{H}$, $\mathrm{K}, \mathrm{M}$ ). Four subjects were overweight 10 $19 \%$ (A, E, G, N). Three subjects were overweight $20-29 \%$ (I, L, O), and four subjects were more than $30 \%$ overweight (D, F, J, Q). For two subjects the height and weight was unknown. There was no difference in the body mass index between those with or without carpal tunnel syndrome ( $p>0.05$, analysis of variance) (table 3).

\section{Operative findings and results}

So far two of the subjects with left-sided carpal tunnel syndrome (B, I) have been operated on (by PA). The operative findings have been consistent with carpal tunnel syndrome; both subjects had marked constriction in the median nerve at the transverse carpal ligament. Sectioning of the transverse carpal ligament led to immediate relief of subjective symptoms; this relief has also persisted after the subjects resumed their job.
We have found carpal tunnel syndrome in a surprisingly high proportion of otherwise healthy butchers. Around half $(53 \%)$ of the butchers studied had subjective symptoms and electrophysiological findings indicating the syndrome. Additional proof was the operative findings and the results of the two subjects operated on. Slightly less than half of the butchers $(47 \%)$ had no subjective symptoms of carpal tunnel syndrome; three of these $(18 \%)$ had subclinical signs of the syndrome however. The nondominant hand was affected in all subjects with the syndrome, and in only one subject was the syndrome more severe on the right side. This occurrence is unusual since the carpal tunnel syndrome usually affects the dominant side (15). This high frequency of carpal tunnel syndrome with a somewhat unusual presentation makes it obvious that this disorder must be occupational in these butchers.

Our material is a relatively small cluster sample of butchers, and it is not adequate for epidemiologic conclusions. The number of subjects with carpal tunnel syndrome is amazingly high, and the syndrome may be overrepresented in this material in comparison to butchers in general. The exposure for this type of work was relatively long; the men had been butchers on the average for 15.3 years, and only four subjects had worked as butchers for ten years or less. In addition they came from two slaughterhouses in the same town, and work methods may be similar, exposing the subjects to similar types of traumata. This study was however not biased by selection of the subjects on the basis of subjective symptoms. All the butchers in the two slaughterhouses were included in the sample, and altogether $89 \%$ participated in the study. It does not seem likely that the subjects who did not participate would have significantly altered the results. In spite of the small number of subjects studied and the shortcomings of the sampling of the subjects, we believe that carpal tunnel syndrome is a relevant occupational disorder in butchers. An epidemiologic study with a larger number of subjects and adequate sampling is indicated. 
We have tried to analyze the factors which might cause carpal tunnel syndrome in butchers. During the removal of the hide from the carcass the left hand holds and tears the hide (fig 1). The tool is held in the right hand, while the carcass is held, lifted, and turned with the left hand (fig 2). The butchers did not consider the cutting with the right hand to be as strenuous as the load on the left hand. According to Phalen (14) prolonged forceful grasping movements may cause thickening of the flexor synovial membrane with in the carpal tunnel. The carpal tunnel is a relatively rigid structure, and an increased diameter of the flexor tendons could result in entrapment of the median nerve.

Another factor which may contribute to the appearance of the syndrome in these butchers is body constitution. The butchers were obese and muscular in comparison to the normal population. In-

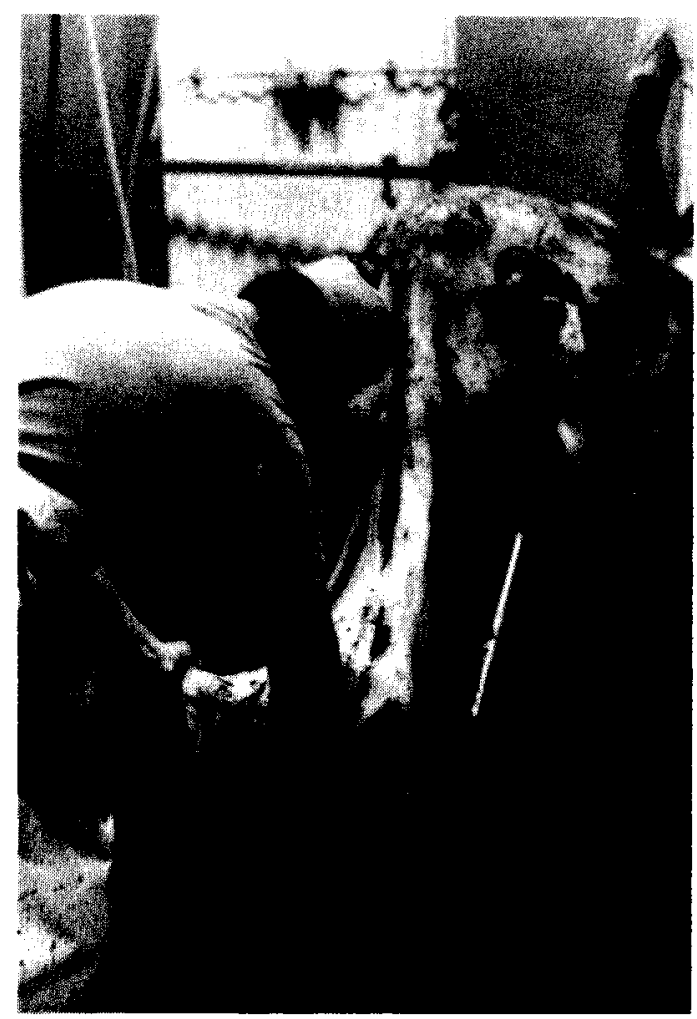

Fig 1. The left hand tears off the hide from the carcass, while the right hand holds the tool. The load on the left hand was considered by all butchers to be heavier than on the right hand, especially during this stage of the process. creased amounts of fatty tissue in the carpal region may lead to a decreased cross-sectional area of the carpal tunnel, an occurrence which could also predispose to carpal tunnel syndrome.

The time spent working as a butcher, as well as the age of the butchers, did not correlate with carpal tunnel syndrome. One reason for this lack of correlation may be that those who have had symptoms may have moved to other types of jobs. This type of selection is indicated by the fact that all four of the subjects who had been butchers for more than 30 years were free of subjective symptoms.

The subjective symptoms correlated well with the electrophysiological findings. All subjects with moderate symptoms of carpal tunnel syndrome also had slowing of the sensory conduction velocity of the median nerve at the wrist. The clinical signs were, however, poorly correlated with carpal tunnel syndrome. The clinical

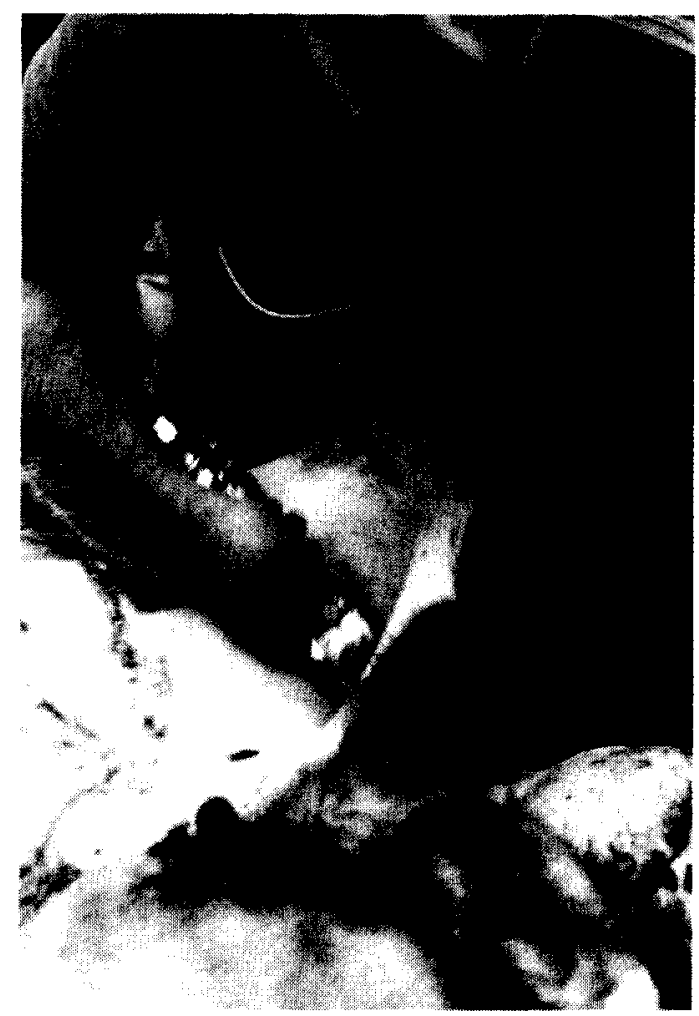

Fig 2. The left hand lifts, turns and holds the carcass, while the right hand holds the tool. 
tests were rarely positive, and there were false positive findings. The clinical tests proved to be of limited value in the diagnosis of the syndrome; this finding is in agreement with that of Sunderland (18).

So far we have not been able to suggest relevant ergonomic improvements which would reduce the mechanical stress on the left hand. Therefore operative treatment is justified. The operation is relatively simple. It can be done under local anesthesia, and it gives permanent relief of the symptoms.

Carpal tunnel syndrome is a relatively common disorder, especially in manual workers. This fact should be taken into account in occupational medicine in studies concerning neuropathies in workers exposed to neurotoxic substances.

\section{References}

1. Beck K. Äetiologie der isolierten AbductorOpponensatrophie am Daumenballen (10 Fälle von Carpaltunnel-syndrom), gleihzeitig ein Beitrag zur sog. Beschäftigungsneuritis bei Zigarrenarbeiterinnen. Dtsch $\mathrm{Z}$ Nervenheilkd 171 (1954) 311-338.

2. Buchtchal F, Rosenfalck A, Trojaborg W. Electrophysiological findings in entrapment of the median nerve at the wrist and elbow. J neurol neurosurg psychiatry 37 (1974) 340-360.

3. Cannon LI, Flenniken A, Track NS. Personal and occupational factors associated with carpal tunnel syndrome. $J$ occup ned 23 (1981) 1397-1401.

4. Gelmers HJ. Primary carpal tunnel stenosis as a cause of entrapment of the median nerve. Acta neurochir 55 (1981) 317-320.

5. Heliövaara M, Aromaa A. Height, weight and obesity of Finnish adults. Social Insurance Institution, Helsinki 1980. (Publications of the Social Insurance Institution,
Finland, ML: 19).

6. Johnson E, Kukla R, Wongsam P, Piedmont A. Sensory latencies to the ring finger: Normal values and relation to carpal tunnel syndrome. Arch phys med rehabil 62 (1981) 206-208.

7. Kendall D. Non-penetrating injuries of the median nerve at the wrist. Brain 73 (1950) 84-94.

8. Knosla T, Lowe CR. Indices of obesity derived from body weight and height. $\mathrm{Br} \mathrm{j}$ prev soc med 21 (1967) 122-128.

9. Kopell HP, Thompson WAL. Peripheral entrapment neuropathies. Williams and Wilkins, Baltimore, MD 1963.

10. Lang H, Kalliomäki JL, Puusa A, Halonen J-P. Sensory neuropathy in rheumatoid arthritis: An electroneurographic study. Scand j rheumatol 10 (1981) 81-84.

11. Lych AC, Lipscomb PR. The carpal tunnel and Colle's fractures. $\mathrm{J}$ am med assoc 185 (1963) $363-368$.

12. Phalen GS. Spontaneous compression of the median nerve at the wrist. J am med assoc 145 (1951) 1128-1134.

13. Phalen GS. The carpal tunnel syndrome. J bone joint surg 48-B (1966) 211-228.

14. Phalen GS. The carpal tunnel syndrome: Clinical evaluation of 598 hands. Clin orthoped relat res 83 (1972) 29-40.

15. Reinstein L. Hand dominance in carpal tunnel syndrome. Arch phys med rehabil 62 (1981) 202-203.

16. Snell N, Coysh H, Snell B. Carpal tunnel syndrome presenting in the puerperium. Practitioner 224 (1980) 191-193.

17. Spaans F. Occupational nerve lesions. In: Vinken PJ, Bruyn G, ed. Handbook of neurology. Volume 7. North Holland Publishing Company, Amsterdam 1970. pp $326-343$

18. Sunderland $\mathrm{S}$. Nerves and nerve injuries. Churchill Livingstone, Edinburgh 1978.

19. Wormser P. Das Karpaltunnelsyndrom. Fortschr Neurol Psychiatr ihrer Grenzgeb 18 (1950) $628-631$.

Received for publication: 19 November 1982 